\title{
Flexible Gas Sensor Array with an Embedded Heater Based in Metal Decorated Carbon Nanofibres
}

\author{
S. Claramunt ${ }^{1}$, O. Monereo ${ }^{1}$, M. Boix ${ }^{1}$, R. Leghrib ${ }^{1}$, J.D. Prades ${ }^{1}$, A. Cornet ${ }^{1}$, P. Merino ${ }^{2}$, C. Merino $^{2}$, \\ A. Cirera ${ }^{1}$ \\ ${ }^{1}$ MIND/IN2UB Electronics Department, Universitat de Barcelona, C/ Martí I Franquès 1, Planta 2, \\ 08028, Barcelona, Spain, \\ Corresponding e-mail autor: sclaramunt@el.ub.es \\ ${ }^{2}$ Grupo Antolín Ingenieria S.A., Burgos, Spain
}

\begin{abstract}
Carbon nanofibres (GANFG) decorated with metal nanoparticles were deposited over Kapton, a polymide flexible substrate, onto which an array of four interdigitated electrodes in one side and a common heater in the backside were printed using inkjet printing technique. The control over metal type and the decoration percentage have given us the possibility to improve the sensor sensitivity and also enhance the selectivity by taking advantages from the difference interaction behaviors of tested target gas molecules with different hybrid materials at room temperature.
\end{abstract}

Key words: carbon nanofibres, metal nanoparticles, gas sensors

\section{Introduction}

In the recent years, great efforts are devoted to develop flexible [1], wireless [2] and selfpowered sensors [3]. Ink-jet printing technique is one of the most used techniques for flexible electronics printing which really cover the gap between standard thick film technology for gas sensors (mainly screen printing) and thin film (microelectronics). In another hand, carbon nanofibres based gas sensors presents the advantages to be operated at room temperature.

The project INFINITEX is aimed to develop a real wearable gas detector that requires many of the above features. This sensor will be integrated in a new generation of garments/jackets that high-risk workers can wear to increase their safety.

\section{Experimental details}

Interdigitated electrodes and heater resistance, in the backside, were ink-jet printed (using Xennia XenJet 4000 ink-jet printer equipped with Xaar Omnidot) on flexible Kapton film (from Dupon) using Sun Chemical silver ink. Carbon nanofibres, provided by Grupo Antolín S.A. [4], were first subject to graphitication process and then decorated with different percentages of $\mathrm{Au}, \mathrm{Pt}$ and $\mathrm{Rh}$ metal nanoparticles from salt precursors using ball-milling. The different hybrid materials resulted from metal decoration process are undergone an annealing treatment of $400^{\circ} \mathrm{C}$ during $3 \mathrm{~h}$, in order to keep the metallic core and evaporate the residues of salt precursors. The obtained powders were diluted in isopropanol which give us stable and homogeneous solutions of diluted materials. The resulted dilutions were sprayed selectively over silver interdigitated electrodes using a mask which permit us also to delimit the deposition area [5]. We used for the deposition of the materials a standard spraying system within the distance between the nozzle and the substrate is $10 \mathrm{~cm}$ and the nitrogen gas flux is 6 $\mathrm{I} / \mathrm{min}$. The deposited layers are subject to light thermal treatment in order to evaporate totally the residues of isopropanol. The control of the spraying parameters results in homogeneous layer of $100 \mathrm{~nm}$ thick. Bare carbon nanofibres are also tested for comparison. The material structure and chemical composition are characterized by TEM using a JEOL JEM 2100 and XPS using a PHI ESCA-5500 respectively. The heater was calibrated using a NEC ThermoShot F30 infrared camera.
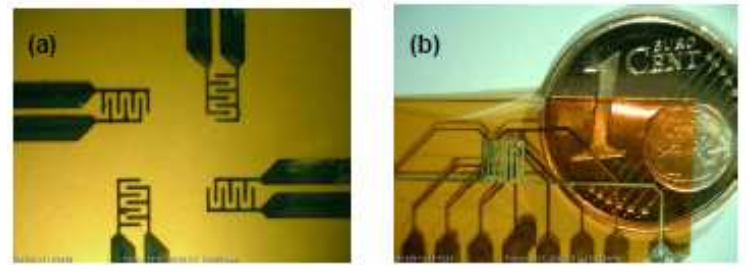

Fig. 1. View of both sides of a flexible device: (a) views of the four sensor array in the top side. (b) The common heater in the backside. 
The sensing properties at room temperature are tested in an environmentally control chamber with high purity (>99.999\%) gaseous mixtures $\left(\mathrm{NH}_{3}, \mathrm{NO}_{2}\right.$ and humidity) diluted in synthetic air.

\section{Results and discussion}

\section{Interdigitated electrodes and heater}

Figure 1 shows the front and back sides of a four printed sensor array with an embedded heater. The interdigitated electrodes have a size of $1 \times 1 \mathrm{~mm}$, meanwhile the heater has an area that permits to cover all the four electrodes at once. In order to calibrate the heater, different powders were applied and, with the help of an infrared camera, the resulting temperature and response were measured. As we can see in Figure 2, the heater responds well and is stable for a temperature range from room temperature up to $150^{\circ} \mathrm{C}$. From this temperature, the heater seems to change its behavior as a relaxation stage appears until it stabilizes to the final temperature. It is a consequence of a sintering process of the silver ink due the high temperatures reached.

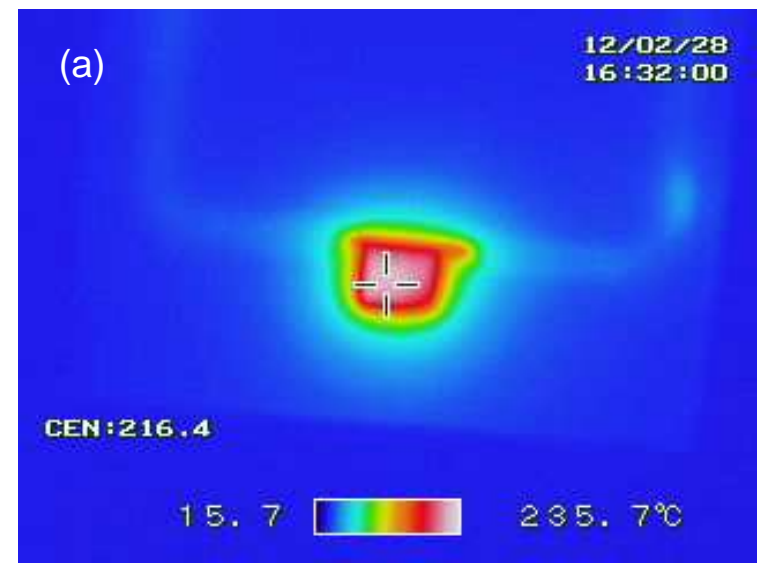

(b)

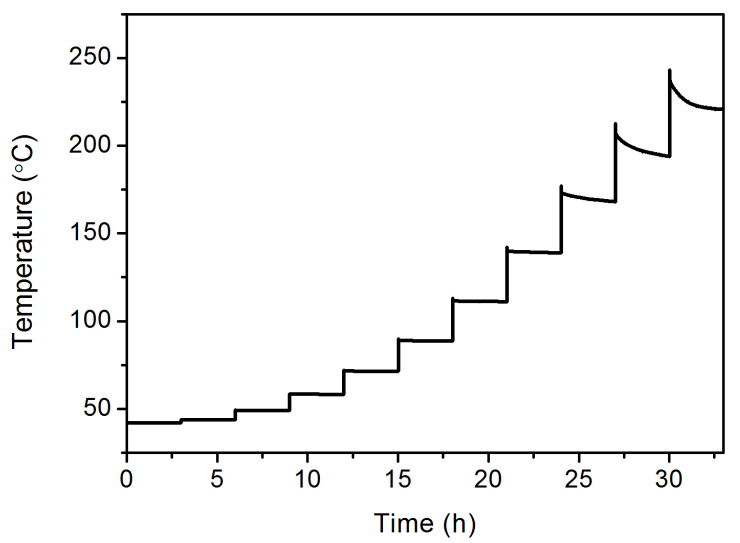

Fig. 2. (a) Infrared image of the heater at around $240^{\circ} \mathrm{C}$. (b) Evolution of the temperature with time. Each pulse corresponds with a change with the power applied.

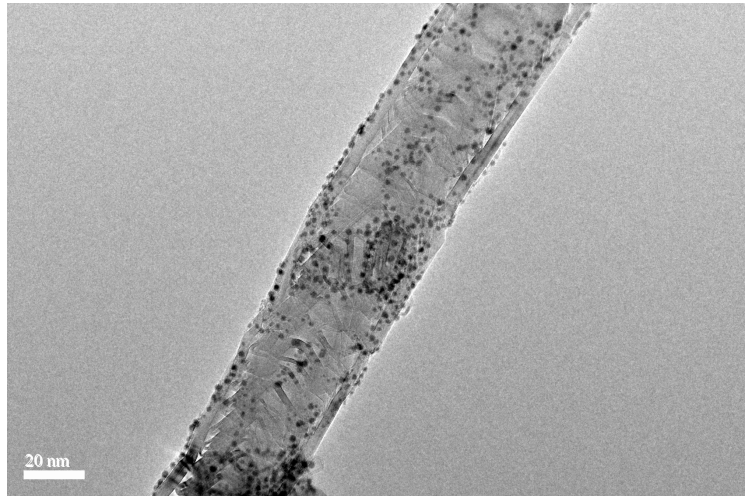

Fig. 3. TEM image of GANFG decorated with $A u$ nanoparticles.

\section{Carbon nanofibres decoration}

In order to decorate the GANFG we used the following procedure: first, GANFG were diluted in acetone in a concentration of $1 \mathrm{mg} / \mathrm{ml}$ and left in continuous stirring. Then, the salts precursors were added in the desired concentration (2\% for the Au metalorganic and $10 \%$ for $\mathrm{PdCl}_{2}$ ), and left stirring during 2 hours. The resulting solution was then subjected to a ball-milling process. Although this process may damage the nanofibres, also can give the sufficient energy to wet the GANFG surface with the metalorganic salt. We found that a ballmilling process of $3 \mathrm{~h}$ and $250 \mathrm{rpm}$ is sufficient to obtain a good salt dispersion, meanwhile the damage of the nanofibres is minimum. After the final mix, the acetone is evaporated and the GANFG were annealed during $3 \mathrm{~h}$ at $400^{\circ} \mathrm{C}$. As an example, a TEM image of the GANFG decorated with Au nanoparticles can be seen in Figure 3. XPS analysis reveal that $\mathrm{Au}$ and $\mathrm{Pd}$ metal is over the surface of the nanofibres, meaning that the decoration have been achieved.

\section{Gas sensor test}

After the decoration, the nanofibres were sprayed over the interdigitated electrodes using the procedure described in the section "Experimental details". By this technique we achieved a localized deposition, covering selectively one electrode at a time, as we can see in Figure 4.

With this configuration we measured the response of the GANFG decorated with $\mathrm{Au}$ nanoparticles and $\mathrm{Pd}$ nanoparticles to $\mathrm{NH}_{3}$ and $\mathrm{CO}$ mixed with moisture at $50 \%$. Bare GANFG also have been studied for comparison. The measurements were done at room temperature, with a pulse of $150^{\circ} \mathrm{C}$ only applied between measurements for clean the nanofibre surface. 


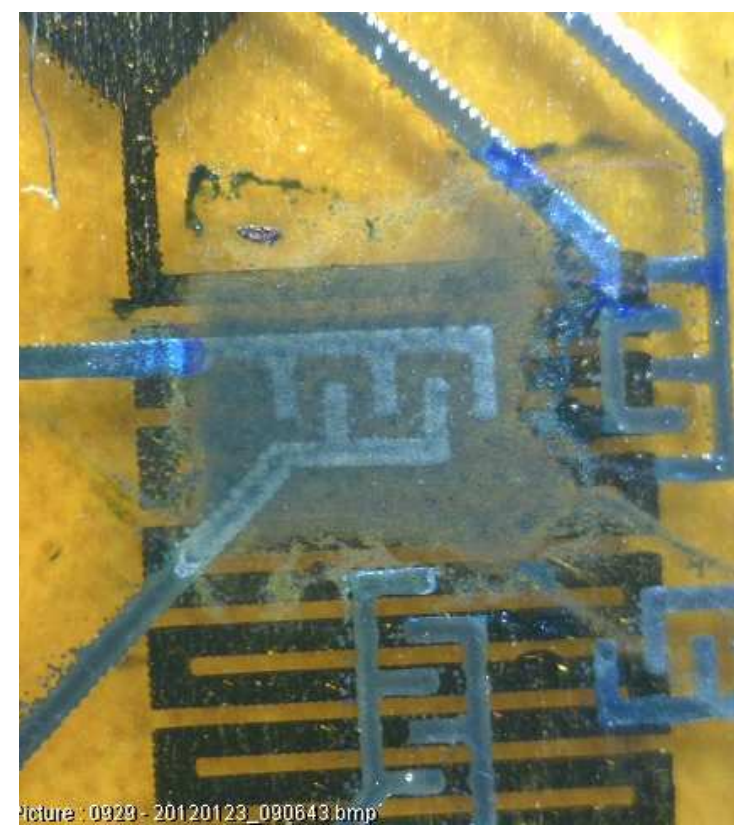

Fig. 4. Thin film of Pd-decorated GANFG.

The Pd decorated GANFG show an increase of the sensitivity of around $10 \%$ towards the $\mathrm{NH}_{3}$ in a concentration level of $500 \mathrm{ppm}$ and $50 \%$ of humidity, respect the bare GANFG. On the other hand, the response against $\mathrm{NO}_{2}(5 \mathrm{ppm}$ and $50 \%$ humidity) slightly decreases.
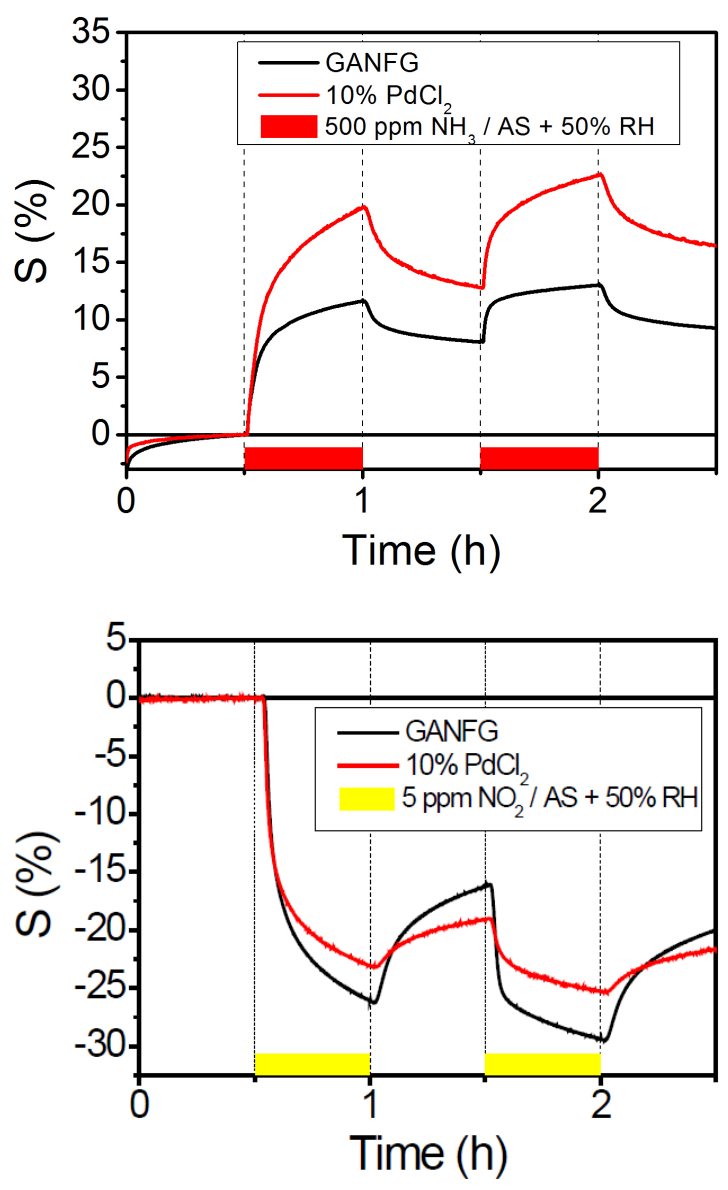

Fig. 4. Responses of GANFG+Pd to $\mathrm{NH}_{3}$ and $\mathrm{NO}_{2}$.
Meanwhile the increase of the response with the $\mathrm{NH}_{3}$ is in agreement with the results reported [6], we obtain an inverse tendency with the $\mathrm{NO}_{2}$ gas. We think that, as we introduce humidity, we obtain the total result, that is a decrease in the sensitivity. We are working in the analysis with only the $\mathrm{NH}_{3}$ and $\mathrm{NO}_{2}$ gases without humidity for determinate the real contribution of the gases and find the real tendency.

Au-decorated GANFG, although that its surface are covered by $\mathrm{Au}$ nanoparticles, little change has been detected in comparison with the bare GANFG. This can be a consequence of the relatively low concentration of metalorganic precursor $(2 \%)$ mixed with the nanofibres during the decoration process. New decorations with higher concentrations are underway.

\section{Acknowledgements}

This work is being developed in the framework of INFINITEX project (Investigación de Nuevas Funcionalidades e Inteligencia Implementadas en Textiles), leaded by Grupo Iturri and financed by Centro para el Desarrollo Tecnológico Industrial from Science and Innovation Ministry. Grateful acknowledgment to the whole consortium and the 11 research centers involved in this project.

\section{References}

[1] T. Fiorido, M. Bendahan, K. Aguir, S. Bernardini, C. Martini, H. Brisset, F. Fages, C. VidelotAckermannC, J. Ackermann, All solution processed flexible ammonia gas and light sensors based on $\alpha, \omega$-hexyl-distyrylbithiophene films, Sensors and actuators B 151, 77 (2010); doi: 10.1016/j.snb.2010.09.048

[2] C. Becher, P. Kaul, J. Mitrovics, J. Warmer, The detection of evaporating hazardous material released from moving sources using a gas sensor network, Sensors and actuators B 146, 513 (2010); doi: 10.1016/j.snb.2009.12.030

[3] Prades, J. D., Jimenez-Diaz, R., HernandezRamirez, F., Barth, S., Cirera, A., RomanoRodriguez, A., Mathur, S., Morante, J. R., Ultralow power consumption gas sensors based on self-heated individual nanowires, Applied Physics Letters 93, 123110 (2008), doi: 10.1063/1.2988265

[4] C. Merino, P. Soto, E. Vilaplana-Ortego, J. M. Gomez de Salazar, F. Pico, J. M. Rojo, Carbon nanofibres and activated carbon nanofibres as electrodes in supercapacitors, Carbon 43, 551 (2005), doi: 10.1016/j.carbon.2004.10.018

[5] I. Jiménez, A. Cirera, A. Cornet, J. R. Morante, I. Gracia, C. Cané, Pulverisation method for active layer coating on Microsystems, Sensors and Actuators B 84, 78 (2002), doi: 10.1016/S09254005(01)01078-4 
[6] Penza, M., Rossi, R., Alvisi, M., Cassano, G., Signore, M.a., Serra, E., Giorgi, R., Pt- and Pdnanoclusters functionalized carbon nanotubes networked films for sub-ppm gas sensors,

Sensors and Actuators B: Chemical 135, 289 (2008), doi: 10.1016/j.snb.2008.08.024 